\title{
Fluid Resuscitation for Trauma Patients: Crystalloids Versus Colloids
}

\author{
Craig Jabaley $\cdot$ Roman Dudaryk
}

Published online: 1 June 2014

(C) Springer Science + Business Media New York 2014

\begin{abstract}
Controversy regarding the role of colloids in the resuscitation of trauma patients has persisted for the past century without a clear resolution. Recently, the early treatment goals of traumatic hypovolemic shock have changed with an emphasis on minimal intravenous fluid administration and the avoidance of over-resuscitation. While some clinicians see a role for colloids in this model, others have become wary as evidence mounts against the efficacy and safety of hydroxyethyl starch and human albumin in critically ill patients. We reviewed the history and fundamentals of the crystalloid versus colloid debate and explored the relevant findings from the prominent nontrauma literature with attention to their applicability in the trauma population. Critical appraisal of the trauma-specific colloid literature is offered with a focus on study design and practical utility. Finally, we offer recommendations about the rational selection of fluids for clinicians who treat these challenging patients.
\end{abstract}

Keywords Trauma - Crystalloid · Colloid · Resuscitation · Fluid therapy $\cdot$ Plasma substitutes

C. Jabaley $(\square) \cdot$ R. Dudaryk

Department of Anesthesiology, Perioperative Medicine, and Pain Management, University of Miami Miller School of Medicine,

1611 NW 12th Ave (C-301), Miami, FL 33136, USA

e-mail: cjabaley@partners.org

R. Dudaryk

e-mail: rdudaryk@med.miami.edu

\section{Introduction}

Traumatic injury is a frequent occurrence throughout the world, the third leading overall cause of death in the USA, and the main cause of death in people between ages 1 and 44 [1]. Out of fatalities resulting from trauma, hemorrhage has been suggested as the second most common contributing cause of death, with the majority of mortality occurring within $48 \mathrm{~h}$ of the inciting injury [2,3]. Similarly, hemorrhage was the cause of intraoperative death in $82 \%$ of patients following major trauma in one series [4]. Intravenous crystalloid and colloid solutions play a critical role in pre-hospital care, initial resuscitation, and as an adjunct to transfusion during ongoing resuscitative efforts. While there is considerable worldwide variability in preference for resuscitation with either crystalloid or colloid, and for the types of colloids preferred, the utility of albumin and hydroxyethyl starch (HES) in trauma patients will be reviewed herein [5].

\section{Background}

The Science of Intravenous Fluids: A Brief Summary

The Starling equation, which links net fluid movement between compartments with capillary versus interstitial hydrostatic and oncotic pressure, has traditionally been used by proponents of colloid resuscitation to describe fluid dynamics in vivo. The terms crystalloid and colloid trace their origin back to Thomas Graham, who in 1861 described aqueous solutions with the ability to readily diffuse through membranes as crystalloids, versus colloids that did not [6]. While time has shown this definition to be somewhat flawed, the monikers have remained. Crystalloids 
consist of mineral salts in aqueous solution with or without other water-soluble molecules, such as buffers. Following administration, the volume of infusate quickly equilibrates across the entire extracellular fluid (ECF) volume, for which the interstitial compartment accounts for $75 \%$, versus only $25 \%$ for the intravascular compartment. [Note that the terms first, second, and third space refer to the intravascular, extravascular (interstitial plus intracellular), and nonfunctional compartments, respectively]. Colloids contain solutes large enough to exert an oncotic pressure and should confer a hypothetical benefit of prolonged intravascular permanence compared to crystalloids, which forms the foundation of the debate at hand.

Attention has been drawn recently to the role of the endothelial glycocalyx, which forms a carbohydrate-rich barrier along the apical surface of vascular endothelial cells. The glycocalyx itself exerts an oncotic force such that the classic Starling model has required revision [7, 8]. As our understanding of this complex barrier continues to evolve, it has been hypothesized that its integrity can be degraded by inflammatory mediators (following ischemia or during sepsis) or mechanical stress (such as hypervolemia), at which point colloids may not be retained as completely in the intravascular compartment leading to capillary leak and potentially exacerbating tissue edema and fluid accumulation [9, 10]. As proteins are bound within and on the surface of its thick matrix, this may create an endovascular "sealing" effect. It has also been proposed that colloids interact with the glycocalyx in a complicated fashion as evidenced partly by improved coronary blood flow secondary to vasodilatation in a guinea pig heart model following albumin but not HES exposure [11]. While "glycocalyx" has become a buzzword of late and a target of translational research, clinical applications remain sparse at this time [12]. Regardless, the interaction of colloids with the vascular endothelium is not as simple as was once conceived.

\section{Trends in Resuscitation}

Based on the classic model of shock developed in the 1940s by physiologist Carl Wiggers involving induced hypovolemia in anesthetized animals, Tom Shires later demonstrated that crystalloids (in addition to blood transfusion) were necessary to replete ECF losses following prolonged hypotension secondary to controlled hemorrhage $[13,14]$. This concept was adapted for use in military and civilian trauma care, and the timely administration of appreciable crystalloid volumes became standard practice. Subsequent animal models and clinical experience began to suggest that, in cases of uncontrolled hemorrhage, overzealous crystalloid resuscitation disrupted coagulation, worsened bleeding, and contributed to mortality [15]. In a landmark study published in 1994, patients with penetrating trauma for whom resuscitation was delayed until the time operative intervention were more likely to survive [16]. While the concept of delayed resuscitation is now better characterized as hypotensive or damage control resuscitation, a tenuous body of evidence hints that, in penetrating trauma, extensive resuscitation before surgical control of hemorrhage could be counterproductive $[17,18]$. Accordingly, some have envisioned a role for colloids in this setting to limit the total volume of fluid administered prior to hemostasis, which is an old concept with renewed attention [19•].

Historical Perspectives on the Debate and Colloid Development

The first colloid to see significant use in humans followed the research of James Hogan in 1915, who sterilized and diluted warmed bovine gelatin in saline [20]. Hogan was quick to publicly espouse the merits of colloidal resuscitation and traveled extensively throughout the European theater during the First World War to demonstrate the preparation and application of his novel treatment [21]. Concurrently, the English physiologist Bayliss had conducted a series of experiments in animal models of "wound shock," which he remedied by sparingly administering a solution of gum arabic, a derivative of Acacia senegalis tree sap, in saline to supplement intravascular oncotic pressure [22]. A related solution was implemented at forward camps during the final months of World War I, thus marking the first widespread use of resuscitation with colloids [23]. Ultimately, the adoption of gelatin was delayed owing to issues with preparation and storage, and gum arabic was abandoned secondary to its hepatotoxicity and antigenicity $[24,25]$. The first commercially produced synthetic colloidal resuscitation solution polyvinylpyrrolidon was synthesized by the prolific German chemist Walter Reppe in 1939 and later marketed by Bayer under the trade name Periston [26]. Periston was acquired and investigated by US researchers, who recommended against its use owing to tissue accumulation and a short intravascular half-life [27].

Alfred Blalock's work in the 1930s shifted the focus away from Bayliss' conservative and colloid-centric resuscitation practices to the critical role of whole blood (and plasma) in the treatment of hypovolemic shock to support oxygen-carrying capacity [28]. Related efforts toward the fractionation of whole blood, and subsequently plasma, led to the availability of albumin via the Cohn process [29]. While the utility of plasma as a "volume expander" was already well-established, concerns over frequent contamination with hepatitis despite desiccation to facilitate storage, and the clinical utility derived from other fractionation products (such as gamma globulin), made 
albumin, which could be heat sterilized and easily stored, an attractive battlefield alternative during World War II despite increased production cost [30]. Following the aforementioned shortcomings with the synthetic colloids available, attention was drawn at the conclusion of the Second World War to dextran, a complex polysaccharide that was originally developed in Sweden while searching for a safe plasma substitute [31]. Implementation of a plasma production and stockpiling program during the Korean War suffered setbacks due to viral contamination and logistic hurtles. Accordingly, albumin and dextran were used almost exclusively at forward resuscitation facilities during the latter stages of the conflict despite the contemporary recognition that dextran prolonged bleeding time and impaired renal function [32-34].

As alluded to previously, the use of significant quantities of crystalloid for resuscitation after battlefield trauma was not commonplace until the 1960s following research associating the repletion of ECF in shock via isotonic crystalloids with improved survival [14]. This shift in practice (coupled with more aggressive blood product transfusion) reduced the incidence of renal failure and mortality during the Vietnam War; however, a new clinical entity termed "shock lung" was identified following prolonged resuscitation [35]. This came to be known as acute respiratory distress syndrome (ARDS) by the 1970s, and concern grew that iatrogenic crystalloid administration played a role in its etiology. Multiple trials were conducted in the 1980s and 1990s comparing the pulmonary effects of resuscitation with crystalloids versus colloids; however, varied populations, problematic study design and endpoints, and heterogeneous interventions made it difficult to draw conclusions. Large meta-analyses would later demonstrate no difference in the incidence of adverse pulmonary outcomes [36, 37]. However, the majority of trials were conducted in an intensive care unit (ICU) setting, leaving practitioners to wonder about the applicability of this research to trauma patients.

After nearly a century of debate, we are still faced with many of the same quandaries involving the same fluids. Questions linger as to their cost effectiveness, impact on coagulation, association with renal failure, and overall safety. Perhaps most importantly, to what degree can the large body of research from ICU, surgical, and septic patients be accurately extrapolated to the trauma population?

\section{Colloid Use in Modern Critical Care: Implications for Trauma Patients}

\section{Hydroxyethyl Starch: From Boom to Bust}

HES is derived from nonionic amylopectin sourced from either waxy maize or potato, which, when coupled with a crystalloid medium, has enjoyed great popularity over the past 20 years as a volume expander. HES products are described by their percentage in solution, average molecular weight, and number of hydroxyethyl group per glucose molecule (e.g., degree of molar substitution). Formulations with larger molecular weight and degrees of substitution persist longer intravascularly and were the initial targets of pharmaceutical development (Table 1). Hespan (6 \% HES $600 / 0.75$ in $0.9 \%$ saline) and Hextend (6 \% HES 670/0.75 in lactated electrolytes) were the first products approved by the United States Food and Drug Administration (FDA) in 1972 and 1999, respectively. However, first (heta- and hexa-starch) and second (pentastarch) generation HES products were associated with coagulopathy, prolonged storage within the reticulo-endothelial system, and longterm renal impairment [38-41]. Accordingly, efforts were then directed toward the creation of a "third generation" product, which resulted in two tetrastarch formulations: Voluven (6 \% HES 130/0.4 in $0.9 \%$ saline) and Tetraspan (6 \% HES 130/0.42 in Ringer's lactate). After their release, a commercial marketing push was followed by papers espousing a similar efficacy profile to prior HES generations with a reduced likelihood of adverse effects [42-44]. Joachim Boldt, a German anesthesiologist with a long track record of prolific HES research and industry ties, was quick to espouse the benefits of these new products. Boldt later came under scrutiny for failure to secure institutional review board approval for multiple studies, and evidence suggesting widespread data falsification has ultimately led to the retraction of approximately 90 publications [45]. In addition to casting doubt on meta-analyses containing the implicated results, these developments have also served to paint HES in a negative light overall [46••, 47].

These setbacks were followed by the publication of the Scandinavian Starch for Severe Sepsis/Shock (6S) trial, the Crystalloid versus HES Trial (CHEST), and the Crystalloids Morbidity Associated with Severe Sepsis (CRYSTMAS) trial, all of which linked tetrastarch with adverse outcomes [48•, 49•, 50]. When coupled with the Volume Substitution and Insulin Therapy in Severe Sepsis (VISEP) study, which examined the effects of pentastarch, these four large randomized control trials (RCTs) served to cast further doubt on the efficacy and safety of HES [51]. Discussion of their relative merits and weakness lies beyond the scope of this review and has been the subject of much debate $[52,53]$. In summary, these pivotal studies suggest that HES is deleterious in septic or otherwise critically ill patients with an associated increased risk of mortality and renal failure (Table 2). Following a similar move by their European counterpart, the FDA added a boxed warning to all HES products that advises health professionals against their use in patients with critical illness, sepsis, pre-existing renal dysfunction, and severe liver disease [54]. 
Table 1 FDA-Approved hydroxyethyl starch (HES) products

\begin{tabular}{llllllll}
\hline $\begin{array}{l}\text { Trade } \\
\text { name }\end{array}$ & Manufacturer & $\begin{array}{l}\text { HES } \\
\%\end{array}$ & $\begin{array}{l}\text { Mean molecular } \\
\text { weight }(\mathrm{kD})\end{array}$ & $\begin{array}{l}\text { Molar } \\
\text { substitution }\end{array}$ & Diluent & $\begin{array}{l}\text { Year licensed } \\
\text { by FDA }\end{array}$ & $\begin{array}{l}\text { Available as } \\
\text { generic (Y/N) }\end{array}$ \\
\hline Hespan & B. Braun & 6 & 670 & 0.75 & $0.9 \%$ sodium chloride & 1972 & Y (Teva) \\
Hextend & BioTime & 6 & 600 & 0.75 & $\begin{array}{l}\text { Lactated electrolyte solution } \\
1999\end{array}$ & $\mathrm{~N}$ \\
Voluven & Fresenius Kabi & 6 & 130 & 0.4 & $0.9 \%$ sodium chloride & 2007 & $\mathrm{~N}$ \\
\hline
\end{tabular}

FDA United States Food and Drug Administration, $k D$ kilodaltons

Replacement Ratios: Sparse Volume-Sparing

Traditional teaching holds that crystalloids must be administered in a 3:1 ratio to achieve similar intravascular volume expansion as that of whole blood or colloids. This dictum stems largely from old and limited experimental animal models but nevertheless has been longperpetuated $[14,55,56]$. Accordingly, one point often argued in favor of colloids is that their greater oncotic pressure and prolonged intravascular presence should result in a "volume-sparing" effect. However, in clinical practice, the ratio of crystalloid to colloid needed to achieve similar hemodynamic parameters appears to be smaller. In the VISEP, 6S, CHEST, CRYSTMAS, and CRISTAL trials, patients received, respectively, an approximate 1.4:1, 1.1:1 (non-significant), 1.15:1, 1.2:1, and 1.5:1 ratio of crystalloid to colloid to obtain similar resuscitative endpoints in ICU patients [48-51, 57]. In the Saline Versus Albumin Fluid Evaluation (SAFE) and Albumin Italian Outcome Sepsis (ALBIOS) trials, the ratios of crystalloid to albumin required for resuscitation were 1.4:1 and 1:1 [58, 59•]. Accordingly, colloids appear to confer, at best, a small benefit when examining total fluid administration.

Transfusion Requirements and Coagulopathy:

A Consistent Trend

As mentioned previously, multiple studies have linked the administration of HES to both coagulopathy and increased transfusion requirements in cardiothoracic, general surgical, and septic patients [60-63]. These clinical findings have been paired with in vivo and in vitro investigations as to the effect of HES on coagulation as measured by thromboelastography, which were recently reviewed [64]. In summary, the authors analyzed 24 studies, 19 of which demonstrated coagulopathy following the administration of hetastarch. While clotting time was not consistently prolonged, weaker clot formation by virtue of impaired platelet aggregation, and fibrin cross-linking was demonstrated in patients who received tetrastarch compared to crystalloids or albumin.

\section{Current Evidence on Colloid Use in Trauma}

Albumin and the SAFE Trial

Albumin has been used widely for resuscitation since its development in the 1940s despite, what might now be considered as, limited clinical investigation before its implementation. In 1998, a Cochrane review linking albumin use in critically ill patients with increased mortality drew incredible attention from the medical community and mainstream press to what was, at the time, a $\$ 1.5$ billion USD worldwide industry $[65,66]$. Sales of albumin subsequently faltered until later meta-analyses emerged that painted albumin in a somewhat more favorable light [36, 67-69]. The SAFE Study aimed to resolve questions from these conflicting analyses [58]. The investigators hypothesized that administration of $4 \%$ albumin or $0.9 \%$ sodium chloride for resuscitation in a multi-center heterogeneous ICU setting would not have an impact on 28-day all cause mortality.

After randomizing nearly 7,000 patients, no significant difference was detected in 28 day mortality, length of ICU admission, or survival times. When comparing albumin and saline within all 1,186 patients with trauma, the relative risk of death in the albumin group was 1.36 but with a confidence interval just crossing unity (0.99-1.86, $P=0.06$ ). Of note, subgroup analysis of trauma patients who had received albumin revealed an increased relative risk of death at 28 days attributed to the $7 \%$ of the study population traumatic brain injury (TBI). A subsequent post hoc follow-up study (SAFE-TBI) also found significantly increased mortality at 24 months [70]. Compared to patients with GCS scores of 9-15, those with scores of 3-8 had significantly worse outcomes. Although, as the authors themselves mention, the relatively small sample size does not support a definitive conclusion, these findings underscore the potential for harm in patients with severe TBI. One theory is that albumin may lead to increased intracranial pressure, reduced cerebral profusion pressure, and thus poor outcomes as examined in a second post hoc analysis (SAFE-TBI II) [71]. 
First and Second Generation HES: Military and Civilian Experiences

As reviewed previously, the military has long employed colloids for resuscitation. Starting in 1996, immediate infusion of one liter of Hespan was advocated for Special Forces medics treating those with shock in the setting of controlled hemorrhage [72]. Subsequent evaluation beginning in 1998 drew attention to HES as an option for initial casualty resuscitation beyond just the special forces arena, and in 2002 the widely employed Tactical Combat Casualty Care (TCCC) guidelines were amended to recommend up to one liter of Hextend [73-76]. Treatment with a volume greater than one liter was not recommended over concerns for coagulopathy and as failure to respond likely suggests poor hemostasis. In addition to heat tolerance, robust packaging, and cost savings over albumin, HES also has an appreciable weight advantage over crystalloids when faced with delayed patient transport owing to its prolonged duration of action, which is a major logistical advantage [76, 77]. Interestingly, up to one half of military pre-hospital providers continue to use crystalloid solutions despite the TCCC recommendations [78].

The first study to examine the efficacy and safety of HES in a civilian setting was conducted in 2008 at Ryder Trauma Center in Miami, Florida [79]. During initial resuscitation, all trauma patients without burns were eligible to receive $500-1,000 \mathrm{ml}$ of open-label Hextend immediately upon arrival at the discretion of the admitting surgeon in addition to SOC with crystalloids and blood products. Ultimately, 1,714 patients with blunt or penetrating trauma were enrolled, 805 received HES, and 909 did not. Univariate analysis showed overall mortality in HES patients to be lower; however, multivariate analysis with logistic regression accounting for other baseline measures and influences on mortality did not demonstrate a significant difference. Patients with penetrating compared to blunt trauma who received HES were found to have lower overall morality (4.4 vs. $13 \%, P=0.0016$ ). However, HES administration was associated with significantly higher rates of ICU admission, blood product transfusion, sepsis, and ARDS. A retrospective review by the same authors found that, in 281 patients requiring emergency surgery after admission for trauma, use of Hextend was associated with anemia, thrombocytopenia, increased likelihood of transfusion, and no difference in mortality [80].

The only other large study to have investigated the effects of resuscitation with hetastarch in trauma came from Shock Trauma at the University of Maryland Medical Center [81•]. In a retrospective fashion, trauma patients admitted to an ICU, with an injury severity score of 9 or greater, and who survived longer than $24 \mathrm{~h}$ were identified. Of those, 491 patients received Hespan. The mean dose of 
HES was $725 \pm 400 \mathrm{ml}$, and blunt trauma accounted for $85 \%$ of all patients. Overall unadjusted in-hospital mortality was higher among patients who received HES and remained significant after adjustment for other variables (1.96, $95 \%$ CI 1.49-2.58, $P<0.0001)$. Sub-group analysis of patients who received HES and did not undergo surgery again demonstrated increased mortality (OR 2.81, $95 \%$ CI 1.89-4.18, $P<0.001)$. Total fluid administration, blood product utilization, and the incidence of acute kidney injury were significantly higher in the HES group. Finally, among patients with TBI, use of HES was associated with increased mortality (OR 2.51, $95 \%$ CI 1.77-3.54).

Both studies have limitations that preclude any definitive statements based on their findings. The Ryder study was neither randomized nor blinded owing to state law that does not allow for community consent. The unavoidable mortality associated with catastrophic traumatic injury and the practical difficulties of retrieving and administering study fluid during that hectic time further increase the likelihood of selection bias. While the authors posit that survival bias may explain the worsened outcomes in patients who received HES, ultimately the study is unable to definitively establish either a safety or efficacy profile for HES in trauma patients. Like any retrospective database review, the Shock Trauma study also has multiple inherent limitations. The authors did not distinguish between blunt and penetrating trauma in their statistical analysis and, given that $85 \%$ of patients who received HES sustained blunt trauma, their findings may be driven by that population. As in the Miami study, they identified an association between HES and increased transfusion requirements. Considering the above finding, use of HES in patients with blunt trauma (possibly including TBI) does not appear to confer a benefit and may be deleterious in several regards.

Although pentastarch formulations are not currently approved by the FDA, two small studies are mentioned herein for the sake of completeness. Examining a total of 64 patients, the effects of HES $10 \%$ 250/0.45 versus crystalloid infusion in the early resuscitation of trauma patients were investigated, and neither study demonstrated a mortality difference [82, 83]. Small study size, use of a hyperoncotic HES preparation, and lack of FDA approval for these solutions severely limit the impact and applicability of these findings to current clinical practice.

Tetrastarch and the Fluids in Resuscitation of Severe Trauma (FIRST) Trial

To date, the FIRST trial is the only published randomized controlled trial to examine the effects of HES in blunt or penetrating trauma patients [84•]. At a single center in Cape Town, South Africa, blunt and penetrating trauma patients who had received a maximum of 2 liters of crystalloid were randomized to receive either HES 130/0.4
(Voluven) or normal saline for further resuscitation. Over the course of three years, 115 of 140 eligible patients were enrolled, and 109 were ultimately analyzed. Of those, 42 patients suffered blunt trauma and 67 had penetrating trauma. No difference in mortality was seen. Patients with penetrating trauma randomized to saline received significantly more fluid within the first $24 \mathrm{~h}$ and had a higher incidence of renal failure (16 vs. $0 \%, P=0.018)$. Per subsequent published communication from the authors, patients with penetrating trauma who received HES demonstrated significantly lower lactate levels versus those who received saline with an average difference of 0.68 (95\% CI 0.07-1.29, $P=0.029$ ) when accounting for the marked differences in baseline lactate levels [85]. Blunt trauma patients who received HES required significantly more blood products within the first $24 \mathrm{~h}$.

It is inadvisable to draw concrete conclusions from the data presented above for several reasons. The study was manufacturer-sponsored and initially designed to primarily address the volume of fluid required for resuscitation and time until return of bowel function with no intent to examine mortality, renal failure, or coagulopathy [86]. While the authors were quick to tout the improvement in lactate clearance and markers of reunal function, most adverse outcomes listed above were downplayed. In addition to the possibility of funding and reporting bias, the study was also likely underpowered to detect renal failure given the small sample size. Marked baseline differences in the blunt trauma arm of the study preclude any determination about the utility or safety of HES in that subset, and findings based on analysis non-randomized subgroups may be skewed. A similar manufacturer-sponsored trial was conducted in 2009; however, results have yet to be published [87].

\section{Conclusion}

Despite the theoretical benefits to resuscitation with colloids, the clinical evidence available does not support their role for resuscitation in trauma or otherwise critically ill patients. We agree with the authors of the recent Cochrane Review that examined the role of colloids for resuscitation in trauma, burn, and surgical patients, which concluded that "as colloids are not associated with an improvement in survival and are considerably more expensive than crystalloids, it is hard to see how their continued use in clinical practice can be justified" [46••]. As reviewed above, the non-trauma literature suggests that neither HES nor albumin confers a meaningful volume-sparing effect. The trend toward increased transfusion requirements likely secondary to coagulopathy is evident in both sets of the literature. Furthermore, the use of even modern HES formulations has been associated with increased mortality and renal failure. 
The initial evidence for the utility and safety of HES following trauma-induced hypovolemic shock was confined to a body of animal studies with varying quality, a review of which is beyond the scope of this discussion. Clinical management based on animal models of colloid resuscitation in shock has led to ultimately false conclusions and deleterious patient outcomes at several points in the history of this debate as summarized previously. Admittedly, there are practical barriers to RCTs in this population: consent, the impact of overwhelming injuries on unavoidable early mortality with subsequent failure of randomization, the conduct of a trial during frenzied resuscitation, and a highly variable patient population. At present, we are faced with a paucity of high-quality clinical studies addressing outcomes of colloid resuscitation in trauma. Based on the available evidence, there appears to be no role for albumin (and perhaps HES) in patients with TBI as evidenced by increased mortality in this patient population, especially in the setting of severe TBI. While the underlying research is problematic, the use of HES in patients with blunt trauma appears non-superior to crystalloids and possibly deleterious as demonstrated most consistently by elevated transfusion requirements likely secondary to coagulopathy. While there may be a role for small volumes of HES during early resuscitation following penetrating trauma, especially when faced with delayed transport, there is not enough evidence to recommend its use in a hospital setting during initial resuscitation, intraoperative care, or in the ICU thereafter, especially when coupled with an established poor safety profile in critically ill patients.

\section{Compliance with Ethics Guidelines}

Conflict of Interest Craig Jabaley and Roman Dudaryk declare that they have no conflict of interest.

Human and Animal Rights and Informed Consent This article does not contain any studies with human or animal subjects performed by any of the authors.

\section{References}

Papers of particular interest, published recently, have been highlighted as:

- Of importance

-• Of major importance

1. Kauvar DS, Wade CE. The epidemiology and modern management of traumatic hemorrhage: US and international perspectives. Crit Care. 2005;9(Suppl 5):S1-9.

2. Sauaia A, Moore FA, Moore EE, Moser KS, Brennan R, Read RA, et al. Epidemiology of trauma deaths: a reassessment. J Trauma. 1995;38(2):185-93.
3. Acosta JA, Yang JC, Winchell RJ, Simons RK, Fortlage DA, Hollingsworth-Fridlund $\mathrm{P}$, et al. Lethal injuries and time to death in a level I trauma center. J Am Coll Surg. 1998;186(5):528-33.

4. Hoyt DB, Bulger EM, Knudson MM, Morris J, Ierardi R, Sugerman HJ, et al. Death in the operating room: an anlysis of a multi-center experience. J Trauma. 1994;37(3):426-32.

5. Finfer S, Liu B, Taylor C, Bellomo R, Billot L, Cook D, et al. Resuscitation fluid use in critically ill adults: an international cross-sectional study in 391 intensive care units. Crit Care. 2010;14(5):R185.

6. Graham T. Liquid diffusion applied to analysis. Phil Trans R Soc Lond. 1861;151:183-224.

7. Michel CC. Starling: the formulation of his hypothesis of microvascular fluid exchange and its significance after 100 years. Exp Physiol. 1997;82(1):1-30.

8. Hu XP, Weinbaum S. A new view of Starling's hypothesis at the microstructural level. Microvasc Res. 1999;58(3):281-304.

9. Köhler M, Kaufmann I, Briegel J, Jacob M, Goeschl J, Rachinger $\mathrm{W}$, et al. The endothelial glycocalyx degenerates with increasing sepsis severity. Crit Care. 2001;15(S3):P22.

10. Nelson A, Berkestedt I, Schmidtchen A, Ljunggren L, Bodelsson M. Increased levels of glycosaminoglycans during septic shock: relation to mortality and the antibacterial actions of plasma. Shock. 2008;30(6):623-7.

11. Jacob M, Rehm M, Loetsch M, Paul JO, Bruegger D, Welsch U, et al. The endothelial glycocalyx prefers albumin for evoking shear stress-induced, nitric oxide-mediated coronary dilatation. J Vasc Res. 2007;44(6):435-43.

12. Becker BF, Chappell D, Bruegger D, Annecke T, Jacob M. Therapeutic strategies targeting the endothelial glycocalyx: acute deficits, but great potential. Cardiovasc Res. 2010;87(2):300-10.

13. Wiggers CJ. The present status of the shock problem. Physiol Rev. 1942;22:74-123.

14. Shires T, Coln D, Carrico J, Lightfoot S. Fluid therapy in hemorrhagic shock. Arch Surg. 1964;88:688-93.

15. Bickell WH. Are victims of injury sometimes victimized by attempts at fluid resuscitation? Ann Emerg Med. 1993;22(2): 225-6.

16. Bickell WH, Wall MJ Jr, Pepe PE, Martin RR, Ginger VF, Allen $\mathrm{MK}$, et al. Immediate versus delayed fluid resuscitation for hypotensive patients with penetrating torso injuries. N Engl J Med. 1994;331(17):1105-9.

17. Kwan I, Bunn F, Roberts I, Committee WHOP-HTCS. Timing and volume of fluid administration for patients with bleeding. Cochrane Database Syst Rev. 2003;3(3):CD002245.

18. Curry N, Hopewell S, Doree C, Hyde C, Brohi K, Stanworth S. The acute management of trauma hemorrhage: a systematic review of randomized controlled trials. Crit Care. 2011;15(2):R92.

19. • Guidry C, Gleeson E, Simms ER, Stuke L, Meade P, McSwain $\mathrm{NE}$, Jr. et al. Initial assessment on the impact of crystalloids versus colloids during damage control resuscitation. J Surg Res. 2013;185(1):294-9. This retrospective study suggests a role for low-volume initial resusciation with HES as an adjunt in patients requiring damage control surgery.

20. Hogan JJ. The intravenous use of colloidal (gelatin) solutions in shock. JAMA. 1915;64(9):721-6.

21. American doctor to save Germans. The New York Times. 1915/7/28.

22. Bayliss WM. Gum injections in "shock". J Nerv Ment Dis. 1919;50(1):88.

23. Van der Kloot W. William Maddock Bayliss's therapy for wound shock. Notes Rec Roy Soc. 2010;64:271-86.

24. Le Gal YM. A review of the history of blood replacement from the 17th to the 20th centuries. Rev Surg. 1975;32(4):229-39.

25. Heckel GP, Erickson CC, Yuile CL, Knutti RE. Blood plasma proteins as influenced by intravenous injection of gum acacia. J Exp Med. 1938;67(3):345-59. 
26. Hecht G, Weese H. Periston, ein neuer blutflüssigkeitsersatz. Münchener Medizinische Wochenschrift. 1943;90:11.

27. National Research Council, editor. Meeting of Subcommittee on Shock Fiscal Year, Committee on Blood and Related Problems, Division of Medical Sciences. Annual Report-National Academy of Sciences-Fiscal Year 1952-1953; 1958; Washington, DC.

28. Johnson GS, Blalock A. Experimental shock IX: a study of the effects of the loss of whole blood, of blood plasma and of red blood cells. Arch Surg. 1931;22(4):626-37.

29. Cohn EJ. The history of plasma fractionation. In: Andrus, editor. Advances in military medicine. Boston: Little, Brown \& Co; 1948.

30. Peters T Jr. Historical perspective. All about albumin: biochemistry, genetics, and medical applications. San Diego: Academic Press; 1996. p. 1-8.

31. Grönwall A. Dextran and its use in colloidal infusion solutions. Uppsala: Almquist and Wiksell, Printers \& Publishers; 1957.

32. Artz CP, Howard JM, Frawley JP. Clinical observations on the use of dextran and modified fluid gelatin in combat casualties. Surgery. 1955;37(4):612-21.

33. Howard JM, Teng CT, Loeffler RK. Studies of dextrans of various molecular sizes. Ann Surg. 1956;143(3):369-72.

34. Vickery AL. The fate of dextran in tissues of the acutely wounded; a study of the histologic localization of dextran in tissues of Korean battle casualties. Am J Pathol. 1956;32(2):161-83.

35. Fishman AP. Shock lung: a distinctive nonentity. Circulation. 1973;47(5):921-3.

36. Choi PT, Yip G, Quinonez LG, Cook DJ. Crystalloids vs. colloids in fluid resuscitation: a systematic review. Crit Care Med. 1999;27(1):200-10.

37. Schierhout G, Roberts I. Fluid resuscitation with colloid or crystalloid solutions in critically ill patients: a systematic review of randomised trials. Brit Med J. 1998;316(7136):961-4.

38. Ertmer C, Rehberg S, Van Aken H, Westphal M. Relevance of non-albumin colloids in intensive care medicine. Best Pract Res Clin Anaesthesiol. 2009;23(2):193-212.

39. Cittanova ML, Leblanc I, Legendre C, Mouquet C, Riou B, Coriat P. Effect of hydroxyethylstarch in brain-dead kidney donors on renal function in kidney-transplant recipients. Lancet. 1996;348(9042):1620-2.

40. Schortgen F, Lacherade JC, Bruneel F, Cattaneo I, Hemery F, Lemaire F, et al. Effects of hydroxyethylstarch and gelatin on renal function in severe sepsis: a multicentre randomised study. Lancet. 2001;357(9260):911-6.

41. Jonville-Bera AP, Autret-Leca E, Gruel Y. Acquired type I von Willebrand's disease associated with highly substituted hydroxyethyl starch. N Engl J Med. 2001;345(8):622-3.

42. Gandhi SD, Weiskopf RB, Jungheinrich C, Koorn R, Miller D, Shangraw RE, et al. Volume replacement therapy during major orthopedic surgery using Voluven (hydroxyethyl starch 130/0.4) or hetastarch. Anesthesiology. 2007;106(6):1120-7.

43. Jungheinrich C, Scharpf R, Wargenau M, Bepperling F, Baron JF. The pharmacokinetics and tolerability of an intravenous infusion of the new hydroxyethyl starch 130/0.4 $(6 \%, 500 \mathrm{~mL})$ in mild-tosevere renal impairment. Anesth Analg. 2002;95(3):544-51.

44. Gallandat Huet RC, Siemons AW, Baus D, van Rooyen-Butijn WT, Haagenaars JA, van Oeveren W et al. A novel hydroxyethyl starch (Voluven) for effective perioperative plasma volume substitution in cardiac surgery. Can J Anaesth. 2000;47(12):1207-15.

45. Wilkes MM, Navickis RJ. The Boldt affair: a quandry for metaanalysts. Anesthesiology News. 2013 April.

46. •• Perel P, Roberts I, Ker K. Colloids versus crystalloids for fluid resuscitation in critically ill patients. Cochrane Database of Systematic Reviews. 2013. http://onlinelibrary.wiley.com/doi/ 10.1002/14651858.CD000567.pub6/abstract. This excellent
Cochrane Review summarizes the findings concerning the role of colloids in trauma, burn, and surgical patients patients and recommends against their routine use.

47. Gattas DJ, Dan A, Myburgh J, Billot L, Lo S, Finfer S. Fluid resuscitation with $6 \%$ hydroxyethyl starch (130/0.4) in acutely ill patients: an updated systematic review and meta-analysis. Anesth Analg. 2012;114(1):159-69.

48. - Perner A, Haase N, Guttormsen AB, Tenhunen J, Klemenzson G, Aneman A et al. Hydroxyethyl starch 130/0.42 versus Ringer's acetate in severe sepsis. N Engl J Med. 2012;367(2):124-34. The 65 trial demonstrated an increase in 90 day mortality and need for renal replacement therapy in septic patients treated with HES.

49. - Myburgh JA, Finfer S, Bellomo R, Billot L, Cass A, Gattas D et al. Hydroxyethyl starch or saline for fluid resuscitation in intensive care. N Engl J Med. 2012;367(20):1901-11. The CHEST trial linked HES use in an ICU setting with worsened renal outcomes but no difference in mortality.

50. Guidet B, Martinet O, Boulain T, Philippart F, Poussel JF, Maizel $\mathrm{J}$, et al. Assessment of hemodynamic efficacy and safety of $6 \%$ hydroxyethylstarch $130 / 0.4$ vs. $0.9 \% \mathrm{NaCl}$ fluid replacement in patients with severe sepsis: the CRYSTMAS study. Crit Care. 2012;16(3):R94.

51. Brunkhorst FM, Engel C, Bloos F, Meier-Hellmann A, Ragaller M, Weiler $\mathrm{N}$, et al. Intensive insulin therapy and pentastarch resuscitation in severe sepsis. N Engl J Med. 2008;358(2):125-39.

52. Chappell D, Jacob M. Twisting and ignoring facts on hydroxyethyl startch is not very helpful. Scand J Trauma Resusc Emerg Med. 2013;21:85

53. Chappell D, Jacob M. Hydroxyethyl starch: the importance of being earnest. Scand J Trauma Resusc Emerg Med. 2013;21:61.

54. United States Food and Drug Administration. FDA Safety Communication: Boxed Warning on increased mortality and severe renal injury, and additional warning on risk of bleeding, for use of hydroxyethyl starch solutions in some settings. 2013.

55. Shires GT, Carrico CJ, Baxter CR, Giesecke AH Jr, Jenkins MT. Principles in treatment of severely injured patients. Adv Surg. 1970;4:255-324.

56. Cervera AL, Moss G. Progressive hypovolemia leading to shock after continuous hemorrhage and 3:1 crystalloid replacement. Am J Surg. 1975;129(6):670-4.

57. Annane D, Siami S, Jaber S, Martin C, Elatrous S, Declere AD, et al. Effects of fluid resuscitation with colloids vs crystalloids on mortality in critically ill patients presenting with hypovolemic shock: the CRISTAL randomized trial. JAMA. 2013;310(17):1809-17.

58. Finfer S, Bellomo R, Boyce N, French J, Myburgh J, Norton R, et al. A comparison of albumin and saline for fluid resuscitation in the intensive care unit. N Engl J Med. 2004;350(22):2247-56.

59. - Caironi P, Tognoni G, Masson S, Fumagalli R, Pesenti A, Romero $\mathrm{M}$ et al. Albumin replacement in patients with severe sepsis or septic shock. N Engl J Med. 2014;370(15):1412-21. The most recent large $R C T$ examining the role of albumin in patients with septic shock found no survival benefit.

60. Wilkes MM, Navickis RJ, Sibbald WJ. Albumin versus hydroxyethyl starch in cardiopulmonary bypass surgery: a metaanalysis of postoperative bleeding. Ann Thorac Surg. 2001; 72(2):527-33; discussion 34.

61. Navickis RJ, Haynes GR, Wilkes MM. Effect of hydroxyethyl starch on bleeding after cardiopulmonary bypass: a meta-analysis of randomized trials. J Thorac Cardiovasc Surg. 2012;144(1): 223-30.

62. Kozek-Langenecker SA, Jungheinrich C, Sauermann W, Van der Linden P. The effects of hydroxyethyl starch 130/0.4 (6\%) on blood loss and use of blood products in major surgery: a pooled analysis of randomized clinical trials. Anesth Analg. 2008;107(2):382-90.

63. Haase N, Perner A, Hennings LI, Siegemund M, Lauridsen B, Wetterslev $M$ et al. Hydroxyethyl starch 130/0.38-0.45 versus 
crystalloid or albumin in patients with sepsis: systematic review with meta-analysis and trial sequential analysis. Brit Med J. 2013;346:f839.

64. Hartog CS, Reuter D, Loesche W, Hofmann M, Reinhart K. Influence of hydroxyethyl starch (HES) 130/0.4 on hemostasis as measured by viscoelastic device analysis: a systematic review. Intensiv Care Med. 2011;37:1725-37.

65. Cochrane Injuries Group Albumin R. Human albumin administration in critically ill patients: systematic review of randomised controlled trials. Brit Med J. 1998; 317(7153):235-40.

66. Yamey G. Albumin industry launches global promotion. Brit Med J. 2000;320(7234):533.

67. Roberts I, Edwards P, McLelland B. Use of human albumin in UK fell substantially when systematic review was published. Brit Med J. 1999;318(7192):1214.

68. Wilkes MM, Navickis RJ. Patient survival after human albumin administration. A meta-analysis of randomized, controlled trials. Ann Intern Med. 2001;135(3):149-64.

69. Vincent JL, Dubois MJ, Navickis RJ, Wilkes MM. Hypoalbuminemia in acute illness: is there a rationale for intervention? A meta-analysis of cohort studies and controlled trials. Ann Surg. 2003;237(3):319-34.

70. Myburgh J, Cooper DJ, Finfer S, Bellomo R, Norton R, Bishop $\mathrm{N}$, et al. Saline or albumin for fluid resuscitation in patients with traumatic brain injury. N Engl J Med. 2007;357(9):874-84.

71. Cooper D, Myburgh J, Heritier S, Finfer S, Bellomo R, Billot L, et al. Albumin resuscitation for traumatic brain injury: is intracranial hypertension the cause of increased mortality? J Neurotrauma. 2013;30(7):512-8.

72. Butler FK Jr, Hagmann J, Butler EG. Tactical combat casualty care in special operations. Mil Med. 1996;161(Suppl):3-16.

73. Butler FK Jr, Hagmann JH, Richards DT. Tactical management of urban warfare casualties in special operations. Mil Med. 2000; 165(4 Suppl):1-48.

74. The Committee on Tactical Combat Casualty Care: 2002. Military Medicine. In: PreHospital Trauma Life Support. St. Louis, MO: Elsevier Mosby; 2004. pp. 374-408.

75. Champion HR. Combat fluid resuscitation: introduction and overview of conferences. J Trauma. 2003;54(5 Suppl):S7-12.

76. Holcomb JB. Fluid resuscitation in modern combat casualty care: lessons learned from Somalia. J Trauma. 2003;54(5 Suppl): S46-51.

77. Pearce FJ, Lyons WS. Logistics of parenteral fluids in battlefield resuscitation. Mil Med. 1999;164(9):653-5.
78. McSwain NE, Champion HR, Fabian TC, Hoyt DB, Wade CE, Eastridge BJ, et al. State of the art of fluid resuscitation 2010: prehospital and immediate transition to the hospital. J Trauma. 2011;70(5 Suppl):S2-10.

79. Ogilvie MP, Pereira BM, McKenny MG, McMahon PJ, Manning RJ, Namais N, et al. First report on safety and efficacy of hetastarch solution for initial fluid resuscitation at a Level 1 trauma center. J Am Coll Surg. 2010;210(5):870-80.

80. Ryan ML, Ogilvie MP, Pereira BM, Gomez-Rodriguz JC, Livingstone AS, Proctor KG. Effect of hetastarch bolus in trauma patients requiring emergency surgery. J Spec Oper Med. 2012; 12(3):57-67.

81. - Lissauer ME, Chi A, Kramer ME, Scalea TM, Johnson SB. Association of $6 \%$ hetastarch resuscitation with adverse outcomes in critically ill trauma patients. Am J Surg. 2011;202(1):53-8. This retrospective study of HES in trauma patients admitted to the ICU demonstrated multiple negative outcomes when compared to resuscitation with saline.

82. Nagy KK, Davis J, Duda J, Fildes J, Roberts R, Barrett J. A comparison of pentastarch and lactated Ringer's solution in the resuscitation of patients with hemorrhagic shock. Circ Shock. 1993;40(4):289-94.

83. Younes RN, Yin KC, Amino CJ, Itinoshe M, Rocha e Silva M, Birolini D. Use of pentastarch solution in the treatment of patients with hemorrhagic hypovolemia: randomized phase II study in the emergency room. World J Surg. 1998;22(1):2-5.

84. - James MF, Mitchell WL, Joubert IA, Nicol AJ, Navsaria PH, Gillespie RS. Resuscitation with hydroxyethyl starch improves renal function and lactate clearance in penetrating rauma in a randomized controlled study: the FIRST trial (Fluids in Resuscitation of Severe Trauma). Brit Med J. 2011;107(5):693-702. As the first published randomized trial of hetastarch in trauma patients, this study suggests a possible role for HES in penetrating trauma despite multiple design flaws.

85. James MF, Michell WL, Joubert IA, Nicol AJ, Navsaria PH, Gillespie RS. Re: Hydroxyethyl starch in patients with trauma, author's reply. Brit Med J. 2012;108(2):322-4.

86. ISRCTN Register. ISRCTN 42061860, A trial of crystalloid versus colloid fluid solutions for the resuscitation of patients with severe injuries. London, UK. 2009. http://www.controlled-trials. com/ISRCTN42061860/42061860. Accessed 18 Apr 2014.

87. National Library Of Medicine. Identifier NCT00890383, Colloids in Severe Trauma (CIST). Bethesda, MD. 2009. http://clinicaltrials. gov/ct2/show/study/NCT00890383. Accessed 18 Apr 2014. 